Review began 06/24/2021 Review ended 01/23/2022 Published 01/26/2022

๑) Copyright 2022

Vivian $\mathrm{F}$ et al. This is an open access article distributed under the terms of the Creative Commons Attribution License CC-BY 4.0., which permits unrestricted use, distribution, and reproduction in any medium, provided the original author and source are credited.

\section{Surgical Management of Advanced Achalasia With Sigmoid Esophagus: A Case Report}

\author{
Lu Vivian $F^{1}$, Dushyant S. Dahiya ${ }^{2}$, Connor B. Shea ${ }^{1}$, Faiz Tuma ${ }^{1}$ \\ 1. General Surgery, Central Michigan University College of Medicine, Saginaw, USA 2. Internal Medicine, Central \\ Michigan University College of Medicine, Saginaw, USA
}

Corresponding author: Connor B. Shea, shea1cb@cmich.edu

\begin{abstract}
The surgical management of achalasia with sigmoid esophagus involves multiple significant challenges due to the difficulty in endoscopic assessment, esophageal motility disorders, and potential complication and recurrence rates. We report a 34-year-old female with worsening dysphagia and malnourishment due to advanced achalasia. An esophagogastroduodenoscopy (EGD) revealed an esophageal dilation, tortuosity, and distal blockage with undigested food. Esophagram demonstrated the typical bird beak appearance with a tortuous dilated esophagus. She underwent a laparoscopic Heller myotomy with Dor fundoplication with no complications. She was discharged on the second postoperative day, tolerating clear liquids, and then a normal diet within six weeks. Several treatment options exist for the surgical management of a sigmoid esophagus with achalasia, but there is no clear gold standard. In our case, Heller myotomy with Dor fundoplication provided favorable results, but treatment should be individualized for each case.
\end{abstract}

Categories: Gastroenterology, General Surgery, Anatomy

Keywords: achalasia, sigmoid esophagus, dor fundoplication, heller myotomy, esophagogastroduodenoscopy

\section{Introduction}

Achalasia is a neuromuscular disease of the esophagus characterized by the failure of the lower esophageal sphincter (LES) to relax, along with weak to absent esophageal peristalsis. The incidence and prevalence of achalasia are 1.63/100,000 and 10.82/100,000, respectively [1]. Increased incidence has been reported by recent studies [2]. This is likely due to improved diagnostic tests and clinical awareness. Patients with achalasia present with various degrees of symptoms, the most common of which are dysphagia for solids and liquids, occasional regurgitation of undigested food material, dyspepsia, weight loss, and chest pain [3]. Dysphagia is usually the primary and most important symptom as it occurs in over $90 \%$ of achalasia patients [3]. The type of dysphagia in achalasia is neuromuscular, which occurs with both solids and liquids, as the neuromuscular forces required to propel the bolus effect solids and liquids in a similar fashion [4]. Achalasia may often present with nonspecific gastroesophageal symptoms, which may lead to delay or confusion in the diagnosis with other common alimentary tract diseases. Hence, various investigations are often needed to identify and confirm the diagnosis [4].

Achalasia is caused by various etiological factors that are unclear at times. A multifactorial etiology has been suggested by some studies [2]. However, the diagnostic criteria of achalasia are well-established. Patients suspected of achalasia undergo and are evaluated with a combination of serial tests, including upper gastrointestinal barium study (UGI), esophagogastroduodenoscopy (EGD), and chest computerized tomography (CT) when needed [5]. Ultimately, a definitive diagnosis is made with an esophageal function test (manometry and impedance) [6].

In advanced achalasia, the esophagus gradually dilates in a progressive pattern that can be severe and resemble the shape of a sigmoid. The sigmoid esophagus is defined as an esophageal dilatation of more than $10 \mathrm{~cm}$ and/or tortuous shape [7]. Treatment for advanced stage achalasia with the sigmoid esophagus is challenging. Surgical and non-surgical treatments, such as mechanical pneumatic dilation, botulinum toxin injections, and myotomy, are rendered less effective in the long term, often leading to a need for retreatment [8]. This article presents a case study of a patient with late-stage achalasia and sigmoid esophagus who was successfully treated with laparoscopic Heller myotomy and Dor fundoplication.

\section{Case Presentation}

A 34-year-old female was referred by her primary care provider to the surgical department for a two-year history of dysphagia, intermittent regurgitation of undigested food, epigastric pain, and early satiety. She had a long-standing history of gastroesophageal reflux disease (GERD) controlled with Prilosec. An EGD was attempted on two separate occasions, but both were unsuccessful due to the presence of undigested food in the lower esophagus, even after a two-day fasting period. An upper gastrointestinal (GI) barium study was then performed, which revealed a dilated thoracic esophagus with smooth tapering at the esophageal junction resembling the typical "bird beak" appearance (Figures 1-2) along with a sigmoid esophagus (Figure 3). Based on the radiological and endoscopic findings, the provisional diagnosis of achalasia was made. The 


\section{Cureus}

patient underwent esophageal manometry but revealed poor esophageal function. It could not measure the lower esophageal sphincter resting tone. Although esophageal manometry was unlikely to change the overall treatment strategy, it was performed for confirmation, characterization of the condition, and insurance requirements. Given the patient's continued dysphagia with significant lifestyle impairments and low surgical risk, laparoscopic Heller myotomy and Dor fundoplication were offered to the patient after reviewing the treatment options.

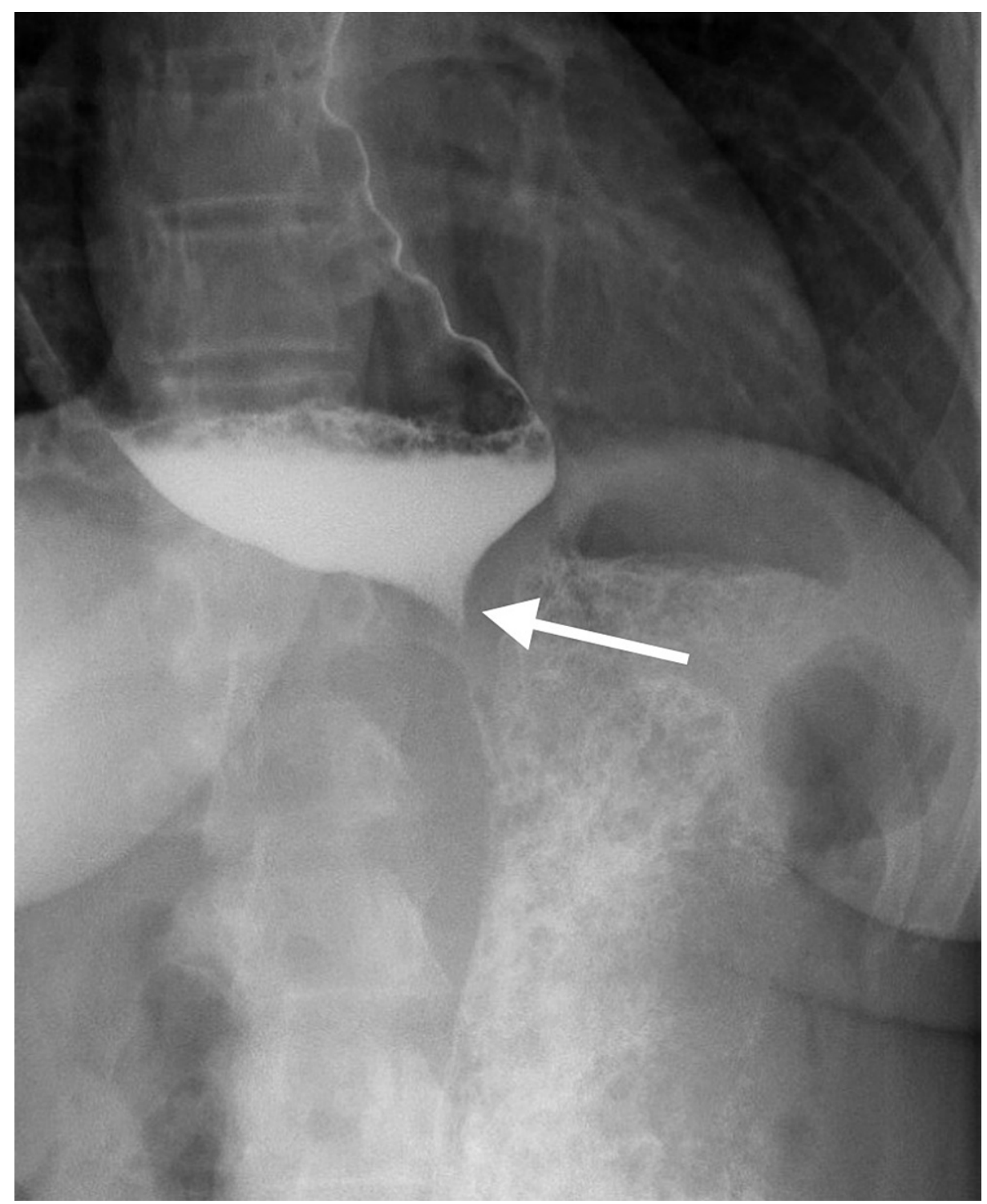

FIGURE 1: A barium swallow depicting the typical "bird's beak" narrowing at the lower esophageal sphincter 


\section{Cureus}

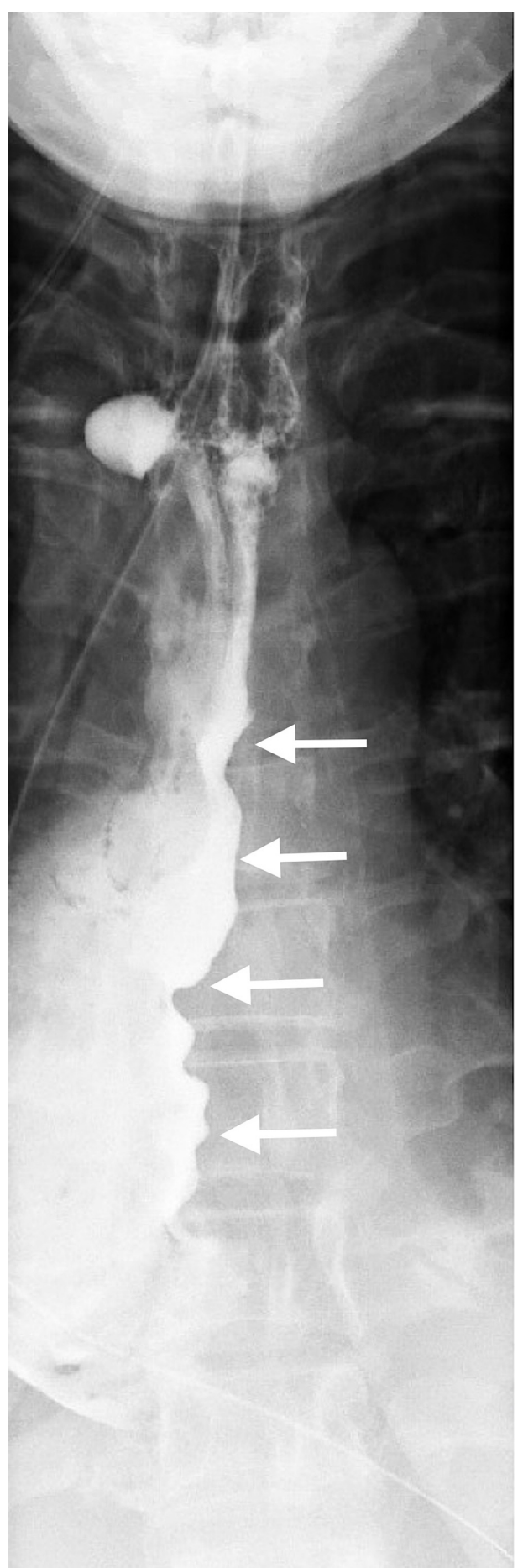

FIGURE 2: A barium swallow showing the dilated tortuous esophagus 


\section{Cureus}

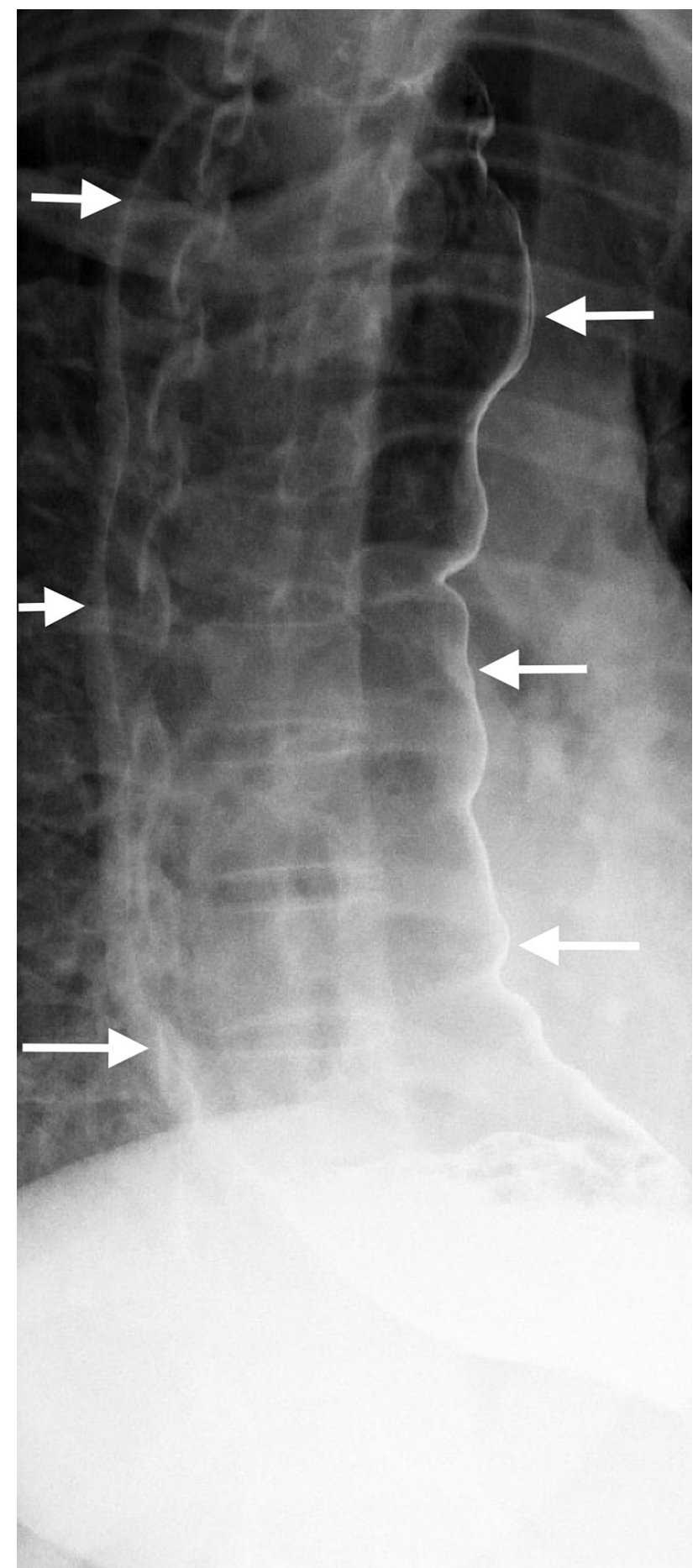

\section{FIGURE 3: Barium swallow of the dilated sigmoid esophagus}

Intraoperatively, the anterior myotomy was completed to $8 \mathrm{~cm}$ on the esophagus and $2.5 \mathrm{~cm}$ at the proximal stomach (Figures 4-5). A cruralplasty to recreate an appropriate hiatus with Dor fundoplication was performed. An intraoperative EGD was performed at the end of the procedure and revealed the same previous findings of a dilated and tortuous esophagus with food remnants. The stomach was intubated for the first time due to the straighter lower esophageal end after the mobilization. The integrity of the lower esophagus lumen and wall, the gastroesophageal junction (GEJ), and the stomach was confirmed. The procedure was completed without complications. She had an uneventful postoperative in-hospital course, continued to show improvement, and was able to tolerate clear liquids. The esophagram confirmed easier passage of the contrast to the stomach. Due to an improvement in the patients' overall status, a decision was made to discharge her with instructions to remain on a clear liquid diet for a week and then transition to a full liquid diet. Within six weeks, she was able to tolerate a normal diet without dysphagia or regurgitation and was satisfied with her improvement. 


\section{Cureus}

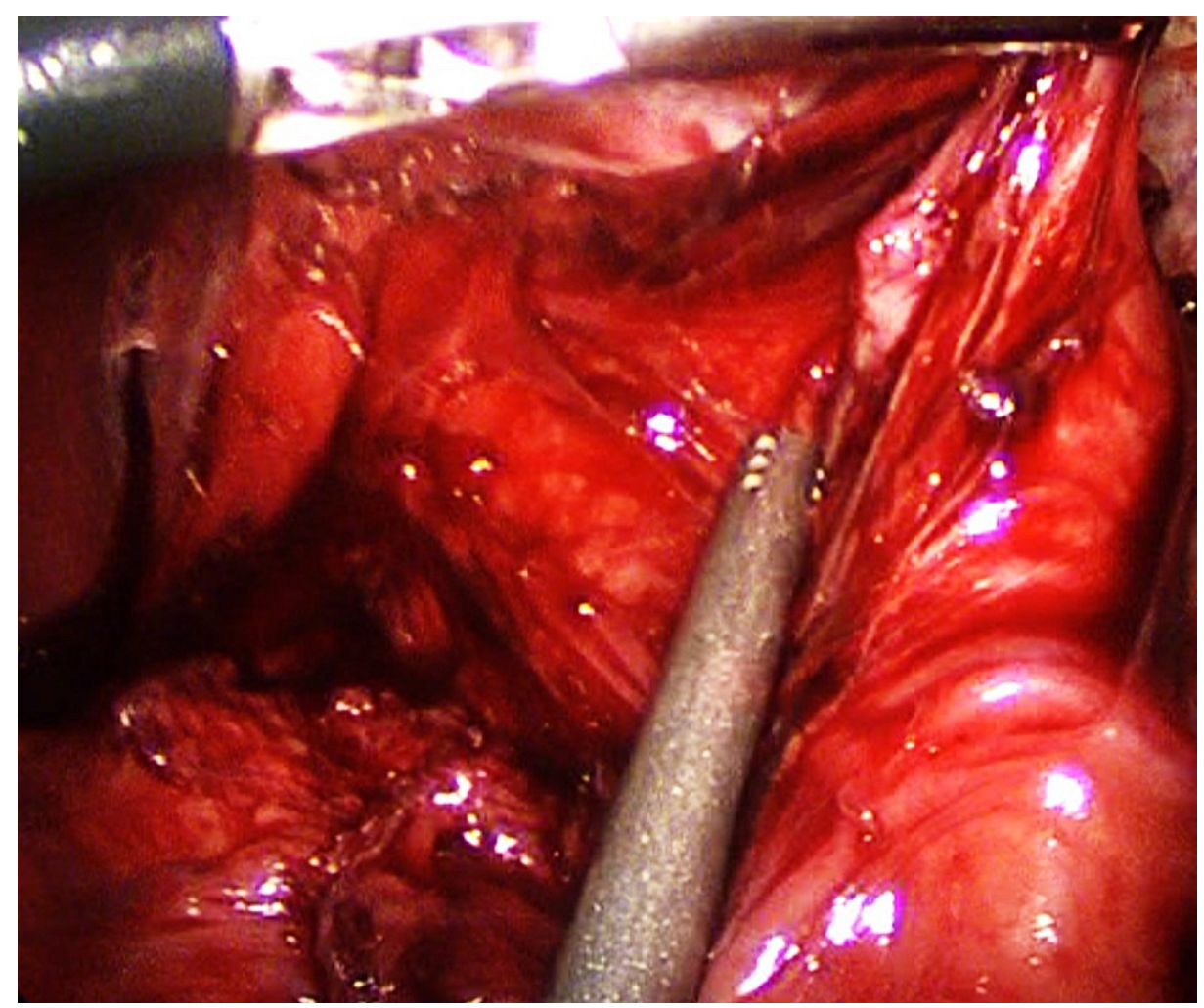

FIGURE 4: The completed $8 \mathrm{~cm}$ esophageal myotomy

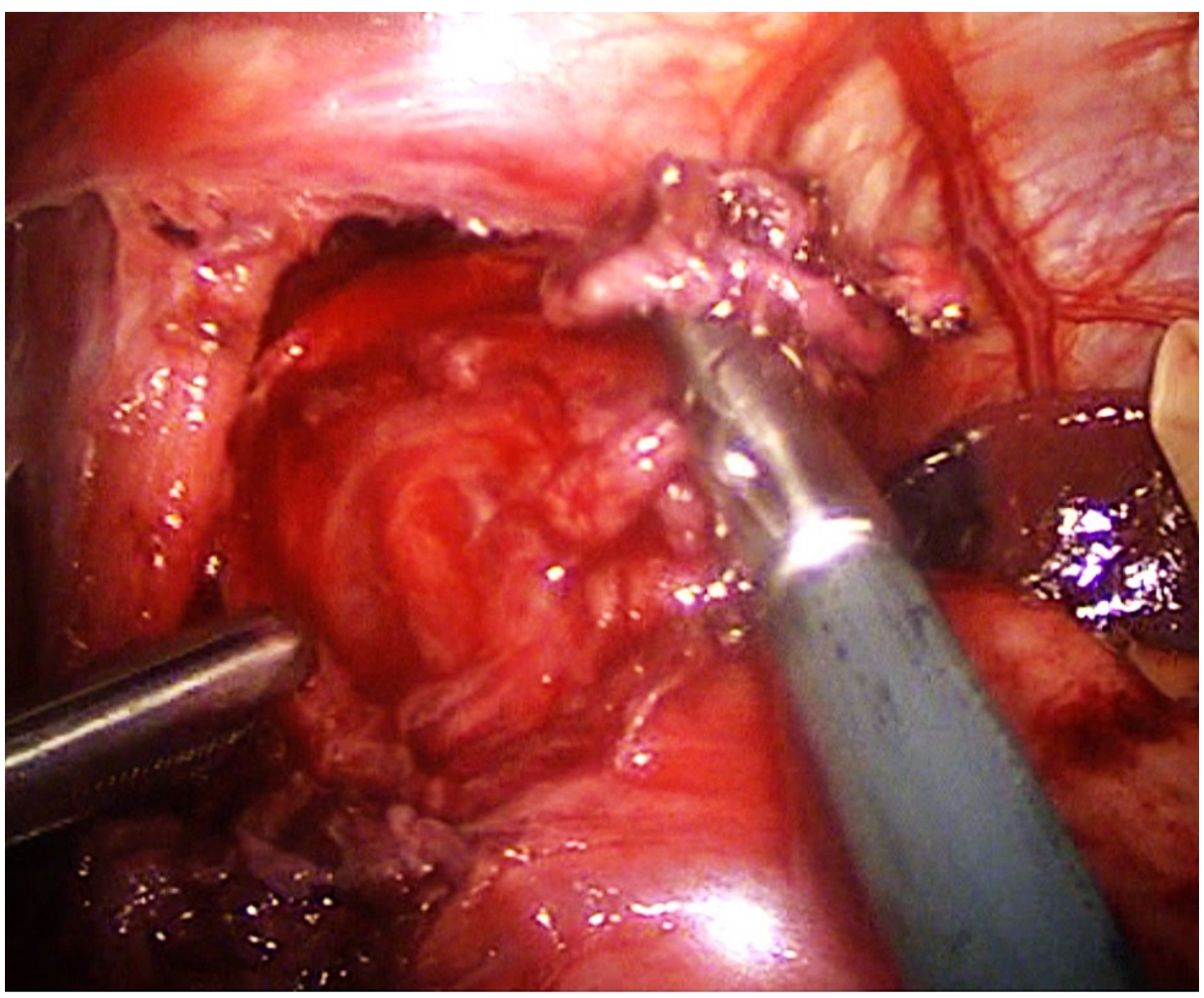

FIGURE 5: Exposed esophageal myotomy after the careful division of the longitudinal muscle fibers of the esophagus

Discussion

Diagnosis of achalasia is unchallenging. UGI series often visualize the esophagus anatomy, including a 
classic "bird beak" appearance of the distal esophagus and esophageal body dilation. In advanced stage achalasia, severe esophageal body dilation results in a sigmoid-like appearance in the distal esophagus [910]. An EGD exam is important to visualize the mucosa and lumen to evaluate for esophagitis, reflux disease, stenosis, and malignancy but is a limited diagnostic tool, as food remnants are relatively common in achalasia $[9,11]$. Manometry as part of the esophageal function test is considered the gold standard test to confirm the diagnosis of achalasia. Lack of esophageal body peristalsis and absent or incomplete relaxation of the LES is the typical finding [1]. Our patient had the typical UGI series and EGD findings. However, manometry could not be completed due to patient intolerance.

The goal of achalasia treatment is to relieve symptoms and improve nutrition, which can be achieved surgically [12]. The main surgical treatment is myotomy of the distal esophagus to release stenosis with the addition of fundoplication to protect from GERD development. Esophagectomy is occasionally considered in advanced cases, however, esophagectomy is associated with significant complications such as persistent regurgitation, anastomotic leakage, and cervical fistula [13]. In our case, the decision was made to proceed with myotomy and Dor fundoplication, as it is a highly effective and safe treatment modality. The endoscopic treatment option was not preferred because of the extremely dilated and thin-walled esophagus, large food stagnation at the distal esophagus, and the necessity of achieving radical improvement. The two edges of the myotomy were widely spaced and the chance of reclosing and scarring was minimal. Also, the exposed esophageal mucosa at the base of the myotomy was fairly thin and would benefit from protection with an anterior wrap - Dor. Ultimately, our experience yielded favorable results that exceeded expectations compared to the expected prognosis.

\section{Conclusions}

Surgical management of severe achalasia with sigmoid esophagus imposes significant challenges. There are several treatment options available, but ongoing controversy yields no clear gold standard. Management should be individualized for each case. In our case, Heller myotomy with Dor fundoplication provided satisfactory symptom improvement and an excellent treatment outcome. Further research and long-term results will be more instructive of the effectiveness of this treatment modality.

\section{Additional Information \\ Disclosures}

Human subjects: Consent was obtained or waived by all participants in this study. Conflicts of interest: In compliance with the ICMJE uniform disclosure form, all authors declare the following: Payment/services info: All authors have declared that no financial support was received from any organization for the submitted work. Financial relationships: All authors have declared that they have no financial relationships at present or within the previous three years with any organizations that might have an interest in the submitted work. Other relationships: All authors have declared that there are no other relationships or activities that could appear to have influenced the submitted work.

\section{References}

1. Sadowski DC, Ackah F, Jiang B, Svenson LW: Achalasia: incidence, prevalence and survival. A populationbased study. Neurogastroenterol Motil. 2010, 22:e256-61. 10.1111/j.1365-2982.2010.01511.x

2. O'Neill OM, Johnston BT, Coleman HG: Achalasia: a review of clinical diagnosis, epidemiology, treatment and outcomes. World J Gastroenterol. 2013, 19:5806-12. 10.3748/wjg.v19.i35.5806

3. Schlottmann F, Neto RML, Herbella FAM, Patti MG: Esophageal achalasia: pathophysiology, clinical presentation, and diagnostic evaluation. Am Surg. 2018, 84:467-72. 10.1177/000313481808400415

4. Chuah SK, Hsu PI, Wu KL, Wu DC, Tai WC, Changchien CS: 2011 update on esophageal achalasia. World J Gastroenterol. 2012, 18:1573-8. 10.3748/wjg.v18.i14.1573

5. Eckardt AJ, Eckardt VF: Current clinical approach to achalasia. World J Gastroenterol. 2009, 15:3969-75. 10.3748/wig.15.3969

6. Akaishi T, Nakano T, Machida T, et al.: Clinical usefulness of endoscopy, barium fluoroscopy, and chest computed tomography for the correct diagnosis of achalasia. Intern Med. 2020, 59:323-8. 10.2169/internalmedicine.3612-19

7. Roll GR, Rabl C, Ciovica R, Peeva S, Campos GM: A controversy that has been tough to swallow: is the treatment of achalasia now digested?. J Gastrointest Surg. 2010, 14 Suppl 1:S33-45. 10.1007/s11605-0091013-5

8. Abud TG, Abud LG, Vilar VS, Szejnfeld D, Reibscheid S: Radiological findings in megaesophagus secondary to Chagas disease: chest X-ray and esophagogram. Radiol Bras. 2016, 49:358-62. 10.1590/01003984.2015.0141

9. Laurino-Neto RM, Herbella F, Schlottmann F, Patti M: Evaluation of esophageal achalasia: from symptoms to the Chicago classification. Arq Bras Cir Dig. 2018, 31:e1376. 10.1590/0102-672020180001e1376

10. Japan Esophageal Society: Descriptive rules for achalasia of the esophagus, June 2012: 4th edition . Esophagus. 2017, 14:275-89. 10.1007/s10388-017-0589-1

11. Herzig MJ, Tutuian R: Focal achalasia - case report and review of the literature . Clujul Med. 2018, 91:120-8. 10.15386/cjmed-867

12. Panchanatheeswaran K, Parshad R, Rohila J, Saraya A, Makharia GK, Sharma R: Laparoscopic Heller's cardiomyotomy: a viable treatment option for sigmoid oesophagus. Interact Cardiovasc Thorac Surg. 2013, 16:49-54. 10.1093/icvts/ivs427 


\section{Cureus}

13. Clayton SB, Castell DO: Multiple good options are available for achalasia management . J Clin Gastroenterol. 2015, 49:194-8. 10.1097/MCG.0000000000000107 